\title{
Spectral domain optical coherence tomography imaging in optic disk pit associated with outer retinal dehiscence
}

This article was published in the following Dove Press journal:

Clinical Ophthalmology

17 October 2014

Number of times this article has been viewed

\author{
Chee Wai Wong ${ }^{1,2}$ \\ Doric Wong ${ }^{1,2}$ \\ Ranjana Mathur ${ }^{1,2}$ \\ 'Singapore National Eye Centre, \\ Singapore; ${ }^{2}$ Singapore Eye Research \\ Institute, Singapore
}

\begin{abstract}
A 37-year-old Bangladeshi male presented with an inferotemporal optic disk pit and serous macular detachment in the left eye. Imaging with spectral domain optical coherence tomography (OCT) revealed a multilayer macular schisis pattern with a small subfoveal outer retinal dehiscence. This case illustrates a rare phenotype of optic disk maculopathy with macular schisis and a small outer retinal layer dehiscence. Spectral domain OCT was a useful adjunct in delineating the retinal layers in optic disk pit maculopathy, and revealed a small area of outer retinal layer dehiscence that could only have been detected on high-resolution OCT.
\end{abstract}

Keywords: retinal imaging, maculopathy, macular schisis

\section{Introduction}

An optic disk pit is a congenital abnormality of the optic nerve head, first described in 1882 by Wiethe ${ }^{1}$ as a gray, white-yellow, or black round depression in the optic disk. ${ }^{2}$ Optic disk pits are extremely rare, with an incidence of one in $11,000 .{ }^{3}$ In 1927 , Halbertsma ${ }^{4}$ described an association of optic disk pit with macular lesions and poor visual acuity, which is now known as optic disk pit maculopathy (ODP-M). ODP-M can develop in $25 \%-75 \%$ of optic disk pits and usually confers a poor visual prognosis, with $80 \%$ of eyes having a final visual acuity of $6 / 60$ or worse, as a result of long-standing serous macular detachment, formation of macular holes, and atrophy of the underlying retinal pigment epithelium. ${ }^{5}$ The morphology of ODP-M has been well characterized by the use of optical coherence tomography (OCT). ${ }^{6}$ ODP-M has a typical bilaminar appearance of retinal schisis and neurosensory detachment, but, commonly, either one of the features exists in isolation. Outer retinal holes or dehiscence are uncommon findings in ODP-M, reported to occur in only $27 \%$ of cases ${ }^{6}$ imaged with time domain OCT (TD-OCT). Spectral domain OCT (SD-OCT) offers high-resolution imaging of the retinal layers, allowing a detailed analysis of the morphology of ODP-M, and may detect small areas of outer retinal dehiscences missed on TD-OCT imaging. We describe a case of ODP-M with a small area of outer retinal dehiscence that was revealed on SD-OCT.

\section{Case report}

A 37-year-old Bangladeshi male with no past medical history of note presented with a central blurring of vision in his left eye since 1 month prior to his visit to the ophthalmology clinic. His best-corrected visual acuity (BCVA) on the Snellen chart was $20 / 20$ in the right eye and 20/400 in the affected left eye. The anterior segment
Singapore National Eye Centre, II Third

Hospital Avenue, Singapore 16875 I

Fax +6562263395

Email ranjana.mathur@snec.com.sg 
examination was unremarkable, and the intraocular pressure on Goldmann applanation tonometry was $18 \mathrm{mmHg}$ in both eyes. A dilated fundal examination of the left eye revealed neurosensory detachment of the macula with scattered subretinal deposits within the area of detachment. An optic disk pit was seen in the inferotemporal aspect of the optic disk, continuous with the area of retinal detachment (Figure 1). The optic disk and fundus of the right eye were normal. SD-OCT (Spectralis HRA-OCT; Heidelberg Engineering, Heidelberg, Germany) revealed outer nuclear layer macular schisis with neurosensory detachment and a small area of outer retinal dehiscence in the foveal region (Figure 2). The outer nuclear layer schisis cavity was communicating with the optic disk pit (Figure 3). Autofluorescence imaging showed isoautofluorescence in the macula with multiple hyperautofluorescent spots (Figure 4) corresponding to the lipofuscin deposits seen on fundal examination. Fundus fluorescein angiography showed temporal parapapillary hyperfluorescence due to leakage from the optic disk pit (Figure 5). A diagnosis of ODP-M with outer retinal dehiscence was made. Treatment options, including surgery, were discussed. The patient was not keen for surgical intervention due to cost issues, and eventually underwent focal argon laser photocoagulation to the temporal optic disk margin. Unfortunately, he did not return for his subsequent review.

\section{Discussion}

Our case illustrates several typical OCT and autofluorescence features of ODP-M. First, our patient had intraretinal fluid accumulation within the outer nuclear layer, which is the most common site of involvement in ODP-M. ${ }^{7}$ Second, there was coexisting neurosensory detachment. This dual morphology is another common finding in ODP-M. ${ }^{7}$ Third,

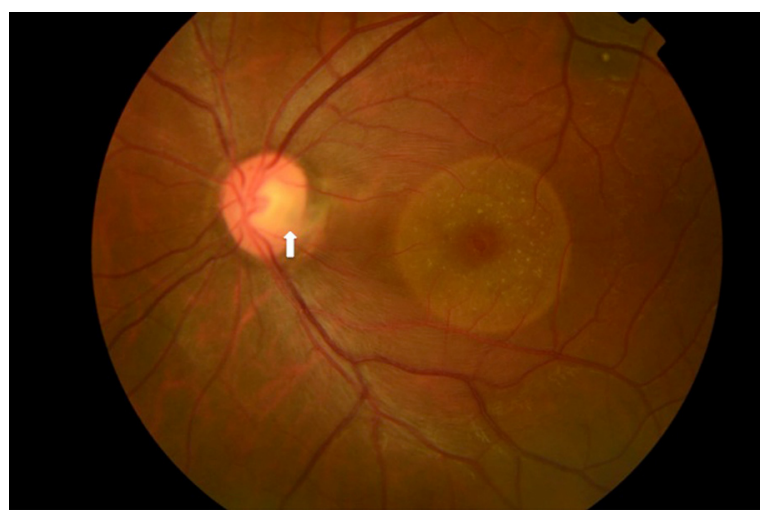

Figure I Fundus photograph of the left eye.

Note: The image shows macular neurosensory detachment with multiple scattered subretinal deposits and an inferotemporal optic disk pit (white arrow). autofluorescence imaging revealed multiple hyperautofluorescent subretinal deposits, which are an almost universal feature of ODP-M. ${ }^{8,9}$ An uncommon finding in our case was that of a small area of subfoveal outer retinal dehiscence that was picked up on high-resolution SD-OCT.

The etiology of ODP-M remains controversial. It is postulated that the possible sources of the intraretinal/subretinal fluid could be the vitreous cavity, ${ }^{9}$ cerebrospinal fluid from the subarachnoid space, ${ }^{10}$ leaky blood vessels at the base of the optic disk pit, ${ }^{11}$ or the orbital space surrounding the dura. ${ }^{12}$ How or why this fluid tracks into the retina is unknown. Postel et $\mathrm{al}^{13}$ proposed that a rhegmatogenous mechanism might be the triggering event by which liquefied vitreous enters the optic disk pit via a small hole in the overlying diaphanous tissue. ${ }^{14}$ Lincoff et al ${ }^{15}$ suggested a sequence of events in the natural history of ODP-M, beginning with fluid accumulation in various retinal layers, with subsequent development of outer retinal dehiscence and movement of fluid through the dehiscence into the subretinal space. ${ }^{14}$

Contrary to Lincoff et al's findings, ${ }^{17}$ outer retinal dehiscence may not be a mandatory step for the occurrence of subretinal fluid accumulation. Most of the earlier studies describing features of ODP-M with TD-OCT do not report the presence of an outer retinal dehiscence, ${ }^{5,15-19}$ with few exceptions. ${ }^{6,20}$ A recent study by Imamura et al utilized OCT to characterize ODP-M in a consecutive series of 16 patients and found outer retinal dehiscence in only $27 \%$ of eyes and presence of subretinal fluid in some patients without outer retinal holes. ${ }^{6}$ However, a variety of OCT machines were used in the study, including TD-OCT and SD-OCT machines. TD-OCT may not have the requisite resolution for imaging small outer retinal holes, possibly contributing to an underestimation of their incidence.

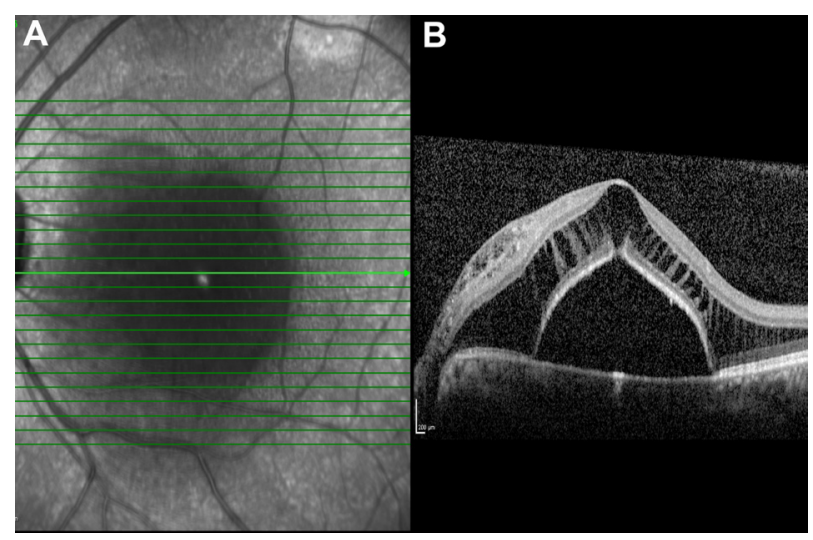

Figure 2 Spectral domain optical coherence tomography scan of the left macula showing outer nuclear layer schisis, a small area of outer retinal dehiscence, and the presence of subretinal fluid. 


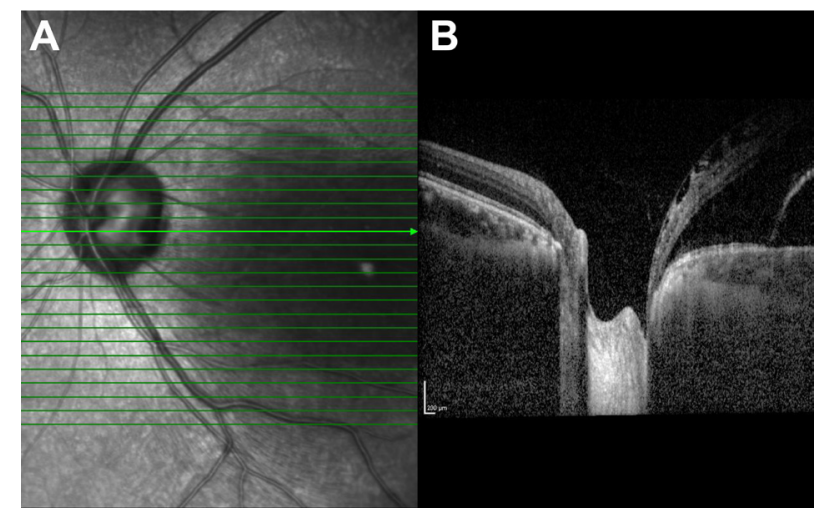

Figure 3 Spectral domain optical coherence tomography scan showing communication between the optic disk pit and the outer nuclear layer schisis cavity.

Twenty-five percent of ODP-M cases resolve spontaneously, ${ }^{2}$ but the poor visual outcome of conservative management ${ }^{21}$ has prompted use of a more aggressive approach. The treatment options range from barrage laser photocoagulation to vitrectomy, with or without adjunctive procedures such as internal limiting membrane (ILM) peel and gas tamponade. Argon laser photocoagulation is applied to the disk margin in the area of the retinal detachment and is believed to cause full-thickness retinal scarring that impedes the flow of fluid, thus allowing the retinal pigment epithelial pump to reabsorb existing fluid. ${ }^{6}$ In most cases, reattachment of the retina occurred, but over a prolonged period of up to $1-2$ years. ${ }^{22,23}$ The release of anteriorposterior traction with pars plana vitrectomy and tangential traction with ILM peel has shown promising anatomical and functional outcomes. ${ }^{7,14}$ Shukla et al performed vitrectomy with ILM peeling, barrage laser photocoagulation, and gas tamponade in a prospective series of seven patients with macular schisis and central outer retinal dehiscence. ${ }^{24}$ Good

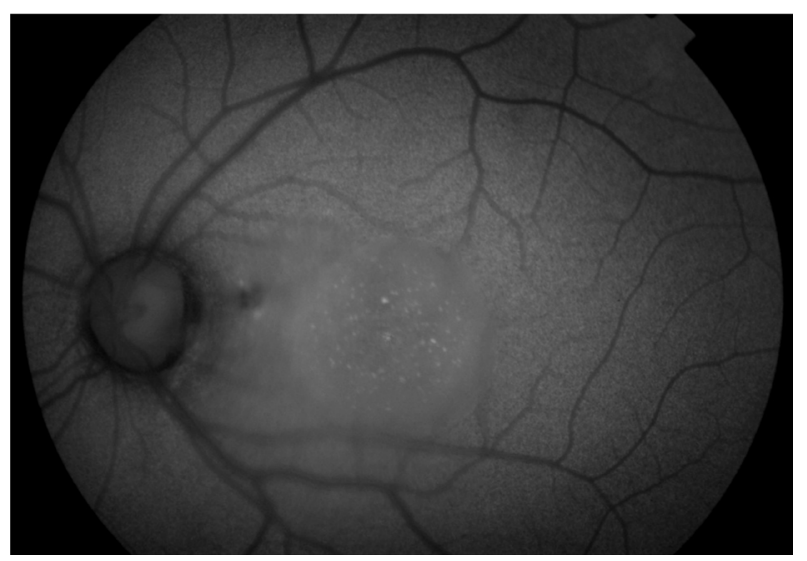

Figure 4 Fundal autofluorescence image of the left eye showing multiple hyperautofluorescent spots within the area of macular detachment.

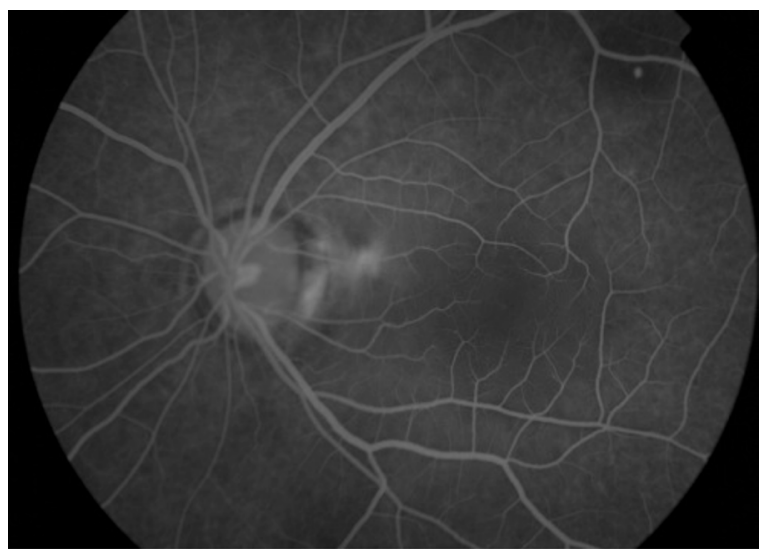

Figure 5 Fundal fluorescence angiogram of the left eye showing parapapillary hyperfluorescence at the temporal optic disk margin.

visual outcomes were achieved, with a median preoperative BCVA of 20/60 improving to a median postoperative BCVA of 20/30. However, four out of seven patients developed fullthickness macular holes (FTMH) postoperatively. The authors attributed the high incidence of FTMH to the peeling of ILM over thinned-out retina. FTMH as a postoperative complication following surgery for ODP-M was similarly reported in other studies. ${ }^{13,21}$ In the absence of strong evidence for any particular treatment, it may be prudent to adopt a graded approach, starting with argon laser photocoagulation and progressing to surgery if the maculopathy fails to resolve. It is also unknown if morphological features, such as multilayered schisis, outer retinal dehiscence, or neurosensory detachment, may necessitate earlier or more aggressive treatment for better visual outcome. Our patient was offered surgical treatment but opted for a more conservative approach of laser photocoagulation first.

\section{Conclusion}

We present a rare phenotype of ODP-M with macular schisis and neurosensory detachment in the presence of a small area of outer retinal dehiscence. SD-OCT was a useful adjunct to diagnosis in ODP-M, and revealed a small area of outer retinal layer dehiscence and the extent of macular schisis. Further studies are needed to explore the significance and impact of structural features in ODP-M on the choice of treatment and visual prognosis.

\section{Acknowledgment}

This manuscript was presented as a poster at the 29th Malaysia-Singapore Joint Ophthalmic Congress 2013, organized jointly by the Malaysia Society of Ophthalmology and the Singapore Society of Ophthalmology, from March 8-10, 2013 (held in Kuala Lumpur, Malaysia). 


\section{Disclosure}

The authors report no conflicts of interest in this work.

\section{References}

1. Wiethe T. Ein Fall von angeborener Difformität der Sehnervenpapille [A case of congenital deformity of the optic disk]. Arch Augenheilkd. 1882;1882(11):14-19. German.

2. Georgalas I, Ladas I, Georgopoulos G, Petrou P. Optic disc pit: a review. Graefes Arch Clin Exp Ophthalmol. 2011;249(8):1113-1122.

3. Kranenburg EW. Crater-like holes in the optic disc and central serous retinopathy. Arch Ophthalmol. 1960;64:912-924.

4. Halbertsma KT. Crater-like hole and coloboma of the disc associated with changes at the macula. Br J Ophthalmol. 1927;11(1):11-17.

5. Theodossiadis GP, Grigoropoulos VG, Liarakos VS, Rouvas A, Emfietzoglou I, Theodossiadis PG. Restoration of the photoreceptor layer and improvement of visual acuity in successfully treated optic disc pit maculopathy: a long follow-up study by optical coherence tomography. Graefes Arch Clin Exp Ophthalmol. 2012;250(7):971-979.

6. Imamura Y, Zweifel SA, Fujiwara T, Freund KB, Spaide RF. Highresolution optical coherence tomography findings in optic pit maculopathy. Retina. 2010;30(7):1104-1112.

7. Roy R, Waanbah AD, Mathur G, Raman R, Sharma T. Optical coherence tomography characteristics in eyes with optic pit maculopathy. Retina. 2013;33(4):771-775.

8. Hiraoka T, Inoue M, Ninomiya Y, Hirakata A. Infrared and fundus autofluorescence imaging in eyes with optic disc pit maculopathy. Clin Experiment Ophthalmol. 2010;38(7):669-677.

9. Laud K, Visaetsilpanonta S, Yannuzzi LA, Spaide RF. Autofluorescence imaging of optic pit maculopathy. Retina. 2007;27(1):116-119.

10. Kuhn F, Kover F, Szabo I, Mester V. Intracranial migration of silicone oil from an eye with optic pit. Graefes Arch Clin Exp Ophthalmol. 2006;244(10):1360-1362.

11. Gass JD. Serous detachment of the macula. Secondary to congenital pit of the optic nervehead. Am J Ophthalmol. 1969;67(6):821-841.

12. Apple DJ, Rabb MF, Walsh PM. Congenital anomalies of the optic disc. Surv Ophthalmol. 1982;27(1):3-41.
13. Postel EA, Pulido JS, McNamara JA, Johnson MW. The etiology and treatment of macular detachment associated with optic nerve pits and related anomalies. Trans Am Ophthalmol Soc. 1998;96:73-88; discussion $88-93$.

14. Rizzo S, Belting C, Genovesi-Ebert F, et al. Optic disc pit maculopathy: the value of small-gauge vitrectomy, peeling, laser treatment, and gas tamponade. Eur J Ophthalmol. 2012;22(4):620-625.

15. Teke MY, Elgin U, Ozdal P, Ozturk F. Autofluorescence and optical coherence tomography findings in optic disc pit-associated maculopathy: case series. Int Ophthalmol. 2011;31(6):485-491.

16. Lincoff H, Lopez R, Kreissig I, Yannuzzi L, Cox M, Burton T. Retinoschisis associated with optic nerve pits. Arch Ophthalmol. 1988;106(1):61-67.

17. Karacorlu SA, Karacorlu M, Ozdemir H, Burumcek E, Esgin H. Optical coherence tomography in optic pit maculopathy. Int Ophthalmol. 2007;27(5):293-297.

18. Theodossiadis PG, Grigoropoulos VG, Emfietzoglou J, Theodossiadis GP. Vitreous findings in optic disc pit maculopathy based on optical coherence tomography. Graefes Arch Clin Exp Ophthalmol. 2007;245(9):1311-1318.

19. Moon SJ, Kim JE, Spaide RF. Optic pit maculopathy without inner retinal schisis cavity. Retina. 2006;26(1):113-116.

20. Rutledge BK, Puliafito CA, Duker JS, Hee MR, Cox MS. Optical coherence tomography of macular lesions associated with optic nerve head pits. Ophthalmology. 1996;103(7):1047-1053.

21. Tzu JH, Flynn HW Jr, Berrocal AM, Smiddy WE, Murray TG, Fisher YL. Clinical manifestations of optic pit maculopathy as demonstrated by spectral domain optical coherence tomography. Clin Ophthalmol. 2013;7:167-172.

22. Mustonen E, Varonen T. Congenital pit of the optic nerve head associated with serous detachment of the macula. Acta Ophthalmol (Copenh). 1972;50(5):689-698.

23. Brockhurst RJ. Optic pits and posterior retinal detachment. Trans Am Ophthalmol Soc. 1975;73:264-291.

24. Shukla D, Kalliath J, Tandon M, Vijayakumar B. Vitrectomy for optic disk pit with macular schisis and outer retinal dehiscence. Retina. 2012;32(7):1337-1342.
Clinical Ophthalmology

\section{Publish your work in this journal}

Clinical Ophthalmology is an international, peer-reviewed journal covering all subspecialties within ophthalmology. Key topics include: Optometry; Visual science; Pharmacology and drug therapy in eye diseases; Basic Sciences; Primary and Secondary eye care; Patient Safety and Quality of Care Improvements. This journal is indexed on Submit your manuscript here: http://www.dovepress.com/clinical-ophthalmology-journal

\section{Dovepress}

PubMed Central and CAS, and is the official journal of The Society of Clinical Ophthalmology (SCO). The manuscript management system is completely online and includes a very quick and fair peer-review system, which is all easy to use. Visit http://www.dovepress.com/ testimonials.php to read real quotes from published authors. 